\title{
Can PSA Predict Bone Metastasis amongst Newly Diagnosed Prostate Cancer Patients?
}

\author{
Daniel Ojuka, Stephen Majicha, Peter Ngugi \\ School of Medicine, University of Nairobi
}

Correspondence to: Dr. Daniel Ojuka, P.O. Box 19762 - 00202, Nairobi, Kenya. Email: danielojuka@gmail.com

\begin{abstract}
Background: The decision as to when a bone scan is necessary in the staging of prostate cancer is controversial with different studies giving varying recommendations on the same subject. Objective: To determine the utility of total Prostate Specific Antigen in the prediction of bone metastases in newly diagnosed prostate cancer patients. Methods: This was a crosssectional descriptive study carried out on newly diagnosed treatment naïve, prostate cancer patients over a period of five months. Patients who had an elevated prostate specific antigen of more than $10 \mathrm{ng} / \mathrm{ml}$, at least six core biopsies and bone scan examinations within one month of the PSA estimation were recruited. The bone scan results were then correlated with tPSA levels and Gleason scores from the histopathology report.
\end{abstract}

\section{Introduction}

Prostate cancer is the second most common male cancer in Kenya with an incidence of 15.2 per 100000 and a mortality rate of 12.2 per 100000 (1). The natural history of prostate cancer is variable among different individuals with most patients suffering a long indolent course of the disease and dying from other causes, unrelated to prostate cancer. In fact, although 60 to 80 percent of 80 -year-olds have histological evidence of prostate cancer, only 3 per cent will actually die from the disease (2). However, other patients suffer an aggressive form of the disease that worsens with time causing significant morbidity and mortality. The lifetime risk for developing a clinically apparent prostate cancer ranges between 5 and $8 \%$ (2). This risk increases with advancing age, family history and dietary factors (low vitamin $\mathrm{D}$, low selenium and high fat diet) (2). The diagnosis of prostate cancer is made on the
Results: Of the 54 patients recruited, only $20 \%$ had positive bone scans. There was statistically significant association between bone scan results and Gleason scores ( $p$ value $=<0.001$ ). The highest sensitivity and specificity was obtained at a PSA cut off of $100 \mathrm{ng} / \mathrm{ml}$, with area under curve of 0.7019 . Conclusion: The results of this study show that PSA may be used in conjunction with Gleason scores as a predictor of the presence of bone metastases.

Key words: Utility, PSA level, Bone scan, Bone metastasis

Ann Afr Surg. 2018; 15(1):4-7

DOI: http://dx.doi.org/10.4314/aas.v15i1.2

(C) 2018 Author. This work is licensed under the Creative Commons Attribution 4.0 International License

grounds of an elevated PSA, digital rectal examination findings, and a positive prostate biopsy with or without the presence of lower urinary tract symptoms. Bones metastasis occurrence is rare in early cancer but has been found to occur in over $80 \%$ of patient with advanced cancer, and when it does occur it reduces the five-year survival to about $3 \%(3-5)$. The traditional way of detecting bone metastases with good sensitivity in our context is bone scan (4). Most patients with prostate cancer in this region present with lower urinary tract symptoms when the disease is fairly advanced. In studies carried out in KNH (Kenyatta National Hospital), majority of patients presented with slate stage $(6,7)$. It is thus probable that a majority of the patients will require bone scans or other radiological examinations to help rule out bony metastases because of this late presentation. However, few studies have 
been done in East Africa to assess the applicability of the internationally recommended bone scan guidelines in the local population. Guidelines are based on systematic review of research evidence and assessment of cost benefits to patient and may differ in the context in which these studies are done. The European Association of Urology (EAU) guidelines, updated in March 2009, recommend that staging bone scan may not be indicated in patients with a PSA of $20 \mathrm{ng} / \mathrm{ml}$ or less with moderately differentiated to well differentiated tumors, in the absence of bony symptoms, while the American Urological Association (AUA) and American Joint Committee on Cancer (AJCC) both recommend that bone scan is indicated in patients with Gleason score greater than 7 or PSA greater than $20 \mathrm{ng} / \mathrm{ml}$ prior to treatment (8). It is uncertain whether these guidelines apply in East Africa because of the known ethnic, racial and regional differences in the pathogenesis of prostate cancer (9).Many centers use a PSA cut-off of $20 \mathrm{ng} / \mathrm{ml}$ and/or a high Gleason score (greater than 6) to perform a bone scan. However, some studies have revealed bone metastasis in patients with PSA levels below $10 \mathrm{ng} / \mathrm{ml}$ in a small proportion of patients (10). Bone metastases cannot be ruled out even in patients with PSA less than $10 \mathrm{ng} / \mathrm{ml}$ (10). There is therefore no clear cut universally agreeable PSA level at which bone metastases are expected to occur. The purpose of this study was to determine the utility of PSA in the prediction of bone metastasis in newly diagnosed prostate cancer patients in the local population.

\section{Methods}

The study was carried out in urology clinics, surgical wards and department of nuclear medicine at Kenyatta National Hospital. Treatment naïve patients referred to the urology clinics from the casualty department or other wards at $\mathrm{KNH}$ with elevated PSA with or without lower urinary tract symptoms were sent for prostate biopsy. Consecutive sampling was carried out among treatment naive patients with elevated PSA (greater than $20 \mathrm{ng} / \mathrm{ml}$ or greater than $10 \mathrm{ng} / \mathrm{ml}$ with Gleason score of 6 and above) and histologically confirmed prostate cancer undergoing bone scintigraphy at $\mathrm{KNH}$ over a period of five months (November 2014-March 2015). Informed consent was sought from the recruited patients or their guardians. We excluded patients who have had previous prostate surgery, hormonal treatment, been on alpha blockers, radiation therapy, and those who declined to give consent for participating in the study. Consecutive sampling of eligible patients was performed until the sample size was reached. All the total PSA tests were performed at the $\mathrm{KNH}$ biochemistry laboratory using the same immunoassay (Elisa) method. Gleason scores was obtained from the University of Nairobi, department of pathology and examined by two pathologists who reach consensus on the final score for the purpose of standardization. Technetium-99 methylene diphosphonate (MDP) was used for the bone scans, applying a similar standard procedure for all the recruited patients. Means and frequencies were determined for the ages of the patients, and for the various PSA categories and Gleason scores. For the purpose of the analysis, the PSA values were grouped into the following categories: 10- $20 \mathrm{ng} / \mathrm{ml}, 21-50 \mathrm{ng} / \mathrm{ml}, 51-100 \mathrm{ng} / \mathrm{ml}, 101-500 \mathrm{ng} / \mathrm{ml}$ and more than $500 \mathrm{ng} / \mathrm{ml}$. Sensitivity, specificity, positive and negative predictive values were determined for the various cut off values of PSA. Statistical analysis was performed using SPSS version 17.0 with $p$ values of 0.05 or less being considered statistically significant.

\section{Results}

A total of 54 patients were enrolled into the study. The mean age was 71.07 years (range 46-96 years, modal age group was 71-80 years). The total PSA measured for the 54 patients ranged between $10.5 \mathrm{ng} / \mathrm{mL}$ to 2420 $\mathrm{ng} / \mathrm{mL}$ while the modal PSA Category was 51$100 \mathrm{ng} / \mathrm{mL}$. The most common Gleason score was 6-7 with a percentage of $48.2 \%(n=54)$, Gleason score of 8 10 were $29.6 \%$ and that of $4-5$ were $22.2 \%$. Eleven (20.4\%) out of the 54 patients had positive bone scans. Although there were no positive bone scans for those who had PSA of $20 \mathrm{ng} / \mathrm{ml}$ or less, there were a number of patient with higher PSA who had negative scans (Table 1). There was no statistical significance between the various PSA levels and bone scan findings ( $\mathrm{p}$ value $=$ 0.247, Fisher's Exact test). However, there was statistically significant direct association between bone scan results and Gleason scores ( $p$ value $=<0.001$ ). Eighty three percent of the patients with Gleason score 
of 4-5 had negative bone scans. All the patients who had a Gleason score of 6-7 had negative bone scans. Fifty six percent of the patients with a Gleason score of 8-10 had positive bone scans. There was statistically significant association between the bone scan results and Gleason score on Fisher's exact test ( $p$ value= $<0.001)$. The ROC curve was obtained by plotting true positives and false positives (1-specificity). The area under curve was 0.7019 , standard error 0.0796 with 95\% Confident Interval (0.5639-0.8202). This means that the validity of the test was fair. PSA cannot therefore be regarded as a good predictor of bone metastases in the study population (Figure 1).

Table 1: Correlation of bone scan results with PSA Levels

\begin{tabular}{|c|l|l|l|l|l|l|}
\hline \multicolumn{2}{|c|}{} & \multicolumn{5}{|c|}{ PSA Categories } \\
\cline { 3 - 7 } \multicolumn{2}{|c|}{} & $\mathbf{1 1 - 2 0}$ & $\mathbf{2 1 - 5 0}$ & $\mathbf{5 1 - 1 0 0}$ & $\mathbf{1 0 1 - 5 0 0}$ & $>\mathbf{5 0 0}$ \\
\hline $\begin{array}{c}\text { Bone } \\
\text { Scan }\end{array}$ & Negative 43(79.6) & $6(100)$ & $15(93.8)$ & $15(68.2)$ & $3(60.0)$ & $4(80.0)$ \\
\cline { 2 - 7 } & Positive 11(20.4) & $0(0.0)$ & $1(6.3)$ & $7(31.8)$ & $2(40.0)$ & $1(20.0)$ \\
\hline Total & $\mathbf{5 4 ( 1 0 0 )}$ & $6(100)$ & $16(100)$ & $22(100)$ & $5(100)$ & $5(100)$ \\
\hline
\end{tabular}

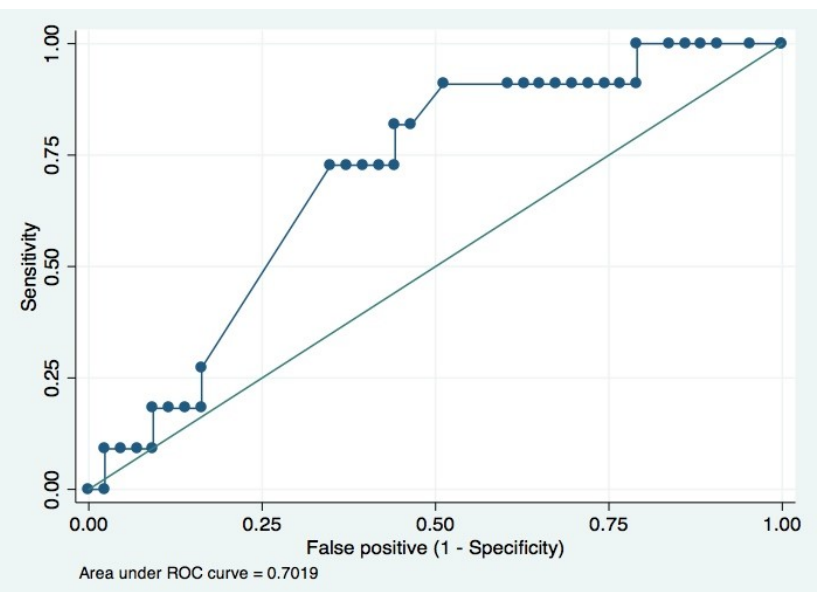

Figure 1: Receiver Operating Characteristic Curve

\section{Discussion}

The results in this study showed wide variations in the PSA levels and bone scan results with only about $20 \%$ of the patients (11 out of 54) recording positive bone scans. All the patients with positive bone scans had a PSA of $50 \mathrm{ng} / \mathrm{ml}$ or more with $63 \%$ of them having their PSA between $51-100 \mathrm{ng} / \mathrm{ml} .83 .7 \%$ of the patients with negative bone scans had a PSA of less than or equal to $100 \mathrm{ng} / \mathrm{ml}$. Just as the AUA and the EUA guidelines are different, several studies have come up with different cut offs of PSA as being predictive of bone metastases as shown in the literature review section above. This can be attributed to the variations in PSA dynamics observed in different populations (9, 11-13). Most published studies have lower PSA cut off $(<20 \mathrm{ng} / \mathrm{ml})$ as a predictor of negative bone scans (12-14).

The best cut off value of PSA obtained from the ROC in this study was $100 \mathrm{ng} / \mathrm{ml}$ (sensitivity of $72 \%$, specificity of $65 \%$ ). Literature reports $68-89 \%$ sensitivity for the bone scan in general (15). The area under ROC curve was 0.7019 (95\% confidence interval 0.56391-0.82022), meaning that PSA test is a fair test for predicting bone metastases in the local population. However, the $p$ value (0.0796) makes the analysis statistically insignificant. This could have resulted from a smaller sample size with a much-skewed data (total PSA range $10.5 \mathrm{ng} / \mathrm{ml}$ to 2420ng/ml).

The Gleason score was an independent predictor of bone metastases with majority of patients with a score of $8-10$ (56\%, 9 out of 16 patients) having positive bone scans and majority of those with a score of 7 and below (94\%, 36 out of 38 patients) having negative bone scans. This was in agreement with other studies done in the United Kingdom (12), Pakistan (13) and Japan (16). One of the limitations of this study is that it was a hospital-based, and had a limited number of patients (patients undergoing bone scans during the study period, 5 months), thus the results obtained are less representative of the true picture in the general Kenyan population, due to the small sample size and patient selection bias. Secondly, the PSA values were obtained on varying days (within 30 days) before the bone scans. This lack of uniformity affected the accuracy of the results as it made the values incomparable. Thirdly the bone scans were reported by a single experienced nuclear medicine physician making it impossible to eliminate observer bias due to the subjective interpretation of the bone scan images

\section{Conclusion}

Total PSA can be a fair test to predict the presence of bone metastases in newly diagnosed prostate cancer patients at $\mathrm{KNH}$ when a cut off of $100 \mathrm{ng} / \mathrm{ml}$ is used. However, the sensitivity of the test can be increased by considering the PSA level together with the Gleason score which is an independent predictor of bone 
metastases. The cut off value of total PSA for the detection of bone metastases in the local population is higher than recommended by both the AUA and the EUA guidelines. Because the data was so skewed, a study with a bigger sample size should be carried out to give a more representative and accurate assessment of the PSA cut off and compensate for this, than what was found in this study. To reduce inconsistencies in the correlation of PSA levels bone scan results, bone scanning and the PSA test should be done on the same day (or within 48 hours of each other) for all the patients. Radionuclide bone scanning should be done based on suggestive symptoms of bone metastases, PSA $>100 \mathrm{ng} / \mathrm{ml}$, Gleason score $>7$ at $\mathrm{KNH}$ in newly diagnosed prostate cancer patients.

\section{References}

1. World Health Organization. International Agency for Research on Cancer [IARC]. Gobocan 2012. Kenyan Statistics. 2008. Available from: http://globocan.iarc.fr/factsheet.asp.

2. Morris PJ, Wood WC. Eds. Oxford Textbook of Surgery.2nd Edition. Pp Oxford University Press 2002.

3. Koo KC, Park SU, Kim KH, et al. Predictors of Survival in Prostate Cancer Patients with Bone Metastasis and Extremely High Prostate-Specific Antigen Levels. Prostate Int. 2015; 3(1):10-5.

4. Nørgaard M, Jensen AØ, Jacobsen JB, et al. Skeletal Related Events, Bone Metastasis and Survival of Prostate Cancer: A Population Based Cohort Study in Denmark (1999 to 2007). J Urol. 2010 Jul 1; 184(1):162-7.

5. Sturge J, Caley MP, Waxman J. Bone Metastasis in Prostate Cancer: Emerging Therapeutic Strategies. Nat Rev Clin Oncol. 2011; 8(6):357-68.

6. Kalande MF. Prostate Specific Antigen in Male Patients over 40 Years with Prostatism at Kenyatta National Hospital (Unpublished Masters of Medicine in Surgery Dissertation), University of Nairobi, 2007.

7. Wasike RW, Magoha GA. Descriptive Case Series of Patients Presenting with Cancer of the Prostate and their Management at Kenyatta National Hospital. East Afr Med J. 2007; 84(Suppl 9): S31-5.
8. Briganti A, Passoni N, Ferrari M, et al. When to Perform Bone Scan in Patients with Newly Diagnosed Prostate Cancer: External Validation of the Currently Available Guidelines and Proposal of a Novel Risk Stratification Tool. Eur Urol. 2010; 57(4):551-8.

9. Kheirandish P, Chinegwundoh F. Ethnic. Differences in Prostate Cancer. Br J Cancer. 2011 Aug 9; 105(4): 481-5.

10. Heidenreich A, Bastian PJ, Bellmunt J, et al. EAU Guidelines on Prostate Cancer. Part 1: Screening, Diagnosis, and Local Treatment with Curative Intent-Update 2013. Eur Urol. 2014; 65(1):12437.

11. Mcarthur C, Mclaughlin G, Meddings RN. Changing the Referral Criteria for Bone Scan in Newly Diagnosed Prostate Cancer Patients. Bri J Radiol. 2012; 85:390-4

12. Lin K-J, Pang S-T, Chang Y-H, et al. Age-Related Reference Levels of Serum Prostate-Specific Antigen among Taiwanese Men Without Clinical Evidence of Prostate Cancer. Chang Gung Med J. 2010; 33(2):182-7.

13. Zaman MU, Fatima N, Sajjad Z. Metastasis on Bone Scan with Low Prostate Specific Antigen $(\leq 20$ $\mathrm{Ng} / \mathrm{Ml})$ and Gleason's Score $(<8)$ in Newly Diagnosed Pakistani Males with Prostate Cancer: Should we Follow Western Guidelines. Asian Pac J Cancer Prev. 2011; 12:1529-32.

14. Ishizuka O, Tanabe T, Nakayama T, et al. ProstateSpecific Antigen, Gleason Sum and Clinical T Stage for Predicting the Need for Radionuclide Bone Scan for Prostate Cancer Patients in Japan. Int J Urol. 2005; 12(8):728-32.

15. Daldrup-Link HE, Franzius C, Link TM, et al. Whole-Body MR Imaging for Detection of Bone Metastases in Children and Young Adults: Comparison with Skeletal Scintigraphy and FDG PET. Am J Roentgenol. 2001;177(1):229-36

16. Hirobe M, Takahashi A, Hisasue S, at al. Bone Scanning-Who Needs it Among Patients with Newly Diagnosed Prostate Cancer? Jpn J Clin Oncol. 2007; 37(10):788-92. 